\title{
A Critical Analysis Of Time Allocation In Psychoeducational Evaluations
}

\author{
Jennifer Valentine, School District of Palm Beach County Florida, USA
}

\begin{abstract}
This study provides results form a national survey examining school psychologists' allocation of time in psycholeducational evaluations. A total of 177 participants with an average of 13.45 years professional experience in school psychology, representing 39 states, participated in the survey. The results indicate that school psychologists spend the majority of their time engaging in test administration and report-writing components of the evaluation process. The data also revealed that the evaluation of students with possible emotional disabilities is most time intensive when compared to evaluations of students with possible learning or intellectual disabilities. Implications of the results relating to policy and procedures to improve the learning outcomes of students in public school settings are provided.
\end{abstract}

Keywords: School Psychology; Psychoeducational Evaluation; Assessment; Time; Testing

\section{INTRODUCTION}

S America's education system evolves, the role of the school psychologist continues to change.
While the school psychologist's primary professional responsibilities are identified as consultation,
evaluation, intervention, prevention, program evaluation, and research, the degree to which school psychologists engage in these activities varies from state to state, and even from district to district (Fagen\& Wise, 2007; Silva, 2003).

One of the reasons for this variability is the expanded role of school psychologists in the response to the intervention process (RTI; Flanagan, Fiorello, \& Ortiz, 2010). Although this expanded role is not new to school psychology, there is variability among school districts and states in the allocation of school psychologists' time in early intervention services, including RTI activities. For example, within some school districts, school psychologists assume an active role in the implementation and monitoring of interventions within a RTI service delivery model. In these school districts, school psychologists are providing direct and indirect services to students, including intervention development, progress monitoring, and data-based decision-making (Fagen \& Wise, 2007), as well as traditional services, such as psychoeducational evaluations. In other school districts, school psychologists continue to work within a more traditional model, providing mainly consultation and assessment-related services, including eligibility decision-making activities. Nevertheless, school psychologists working within an RTI/early intervention service delivery model, or a traditional service delivery model, are both generally spending a portion of their time conducting formal psychoeducational assessments.

As the profession continues to evolve and the services provided by school psychologists expand, it is important to empirically identify how school psychologists spend their time in psychoeducational evaluations. Knowledge of the amount of time school psychologists spend in activities related to psychoeducational evaluations will assist school districts when evaluating current policies and procedures. This may ensure that school psychologists are providing services that have a positive impact on the learning outcomes of as many students as possible within a specific time frame (Imich, 1999).

The collation of data investigating the time allocation of school psychologists in psychoeducational assessment activities is challenging because of the lack of consistency of data collection methods across studies. The 
allocation of school psychologists' time in psychoeducational activities is coded by researchers as hours or minutes spent in a specific activity, percentage of total time in various activities, or the number of activities completed within a specific timeframe (e.g., Fischetti, 2005; Imich, 1999; Smith, 1984; Thomas, 2000). Other researchers provide results indicating the total amount of time required to administer different versions of the same instrument or a specific sample or battery of tests (Axelrod, 1999; Axelrod, 2002; Hutton \& Donders, 2001; Ryan et al., 1998).

What this body of research does not provide is the total amount of time in minutes that school psychologists require to complete psychoeducational evaluations of students suspected of having behavioral/emotional disabilities, learning disabilities, or intellectual disabilities, individually or in combination across a nationally represented sample. The purpose of the present study is to identify the amount of time school psychologists spend in specific components of the psychoeducational evaluation process as well as the total time required to complete evaluations in the areas of behavioral/emotional, learning, and intellectual disabilities across a nationally represented sample of participants.

\section{METHOD}

\section{Participants}

A total of 250 school psychologists attending a national school psychology conference participated in the study; each participant completed a survey. Surveys completed by students, university professors, and retired school psychologists were excluded from data analyses, which resulted in 72 surveys being eliminated from the study. Responses from a total of 178 practicing school psychologist participants were included in the data analyses. The 178 participants had an average of 13.4 (SD 9.6) years of professional experience in school psychology, representing 39 states.

\section{Materials}

Each participant anonymously completed a paper-and-pencil survey. The questions directly asked participants to indicate, in minutes, the amount of time spent in activities related to the completion of a psychoeducational evaluation. The activities were identified as: a) file review; test set-up, locating and escorting the student to the evaluation location setting, and rapport building; b) test administration and report writing; and c) time in team meetings. These activities were stratified across three eligibility areas under IDEIA-2004: behavioral/emotional disability, learning disability, and intellectual disability.

\section{RESULTS}

The study survey provides data indicating the total time, in minutes, each participant engages in four different psychoeducational evaluation activities across three eligibility areas. The results from this survey are presented in Table 1. As indicated in the table, conducting a psychoeducational evaluation for a student suspected of having a behavioral/emotional disability, on average, takes the most time to complete, 355.53 (SD 103.48) minutes, followed by an evaluation to identify/eliminate a learning disability and intellectual disability, 296.26 (SD 77.77) minutes and 285.27 (SD 79.64) minutes, respectively. When compared to the four individual psychoeducational evaluation activities measured by the study, school psychologists spend the majority of the time in test administration, scoring, and reporting writing in combination, which is followed by time in meetings.

\section{DISCUSSION}

This study investigated the number of minute's school psychologists spend in psychodeucational evaluation activities related to the assessment of students suspected of having a learning disability, behavior/emotional disability, or intellectual disability. The results from the study indicate that school psychologists spend, on average, about one hour longer conducting psychoeducational evaluations of students suspected of having a behavior/emotional disability compared to a learning or intellectual disability. As presented in Table 1, the amount of time required to complete each component of a psychoeducational evaluation for a behavior/emotional disability takes longer to complete when compared to psychoeducational evaluation components associated with learning and intellectual disabilities. For example, school psychologists spend more time reviewing a file for a student suspected 
of experiencing a behavior/emotional disability when compared to learning or intellectual disability. Hypothesized reasons for this additional time may include time spent reading and documenting the results from behavioral interventions, norm-referenced behavior scales, behavior observations, teacher notes, and results from socialemotional interviews.

Further visual analysis of the results presented in Table 1 identifies variability around the average total time, in minutes, required to complete each component of a psychoeducational evaluation. The lowest variability, reported as standard deviations, is for test set-up (organization of assessment materials for standardized administration), locating the student to be evaluated, and building rapport, in combination. This means, for example, that to complete these activities for a student suspected of having a learning disability, it takes, on average, 23.26 minutes. However, when the variability of respondents' range of scores is taken into consideration, it will take $68 \%$ of all school psychologists between 9.66 minutes (average time minus one SD) and 37.32 minutes (average time plus one SD) to complete these activities. The greatest variability is within average total time required to complete a psychoeducational evaluation. Within this category, the eligibility area with the most variability is a behavior/emotional disability which takes $68 \%$ of all school psychologists, included in the study, between 252.05 minutes ( 4.2 hours) and 459.01 minutes ( 7.65 hours) to complete.

\section{IMPLICATIONS}

The results from this study indicate that there is much variability across the country in the amount of time school psychologists spend in each component within a psychoeducational evaluation. This variability may be due, in part, to differences in the policy and procedures that school districts/systems and/or the state department of education have in place to ensure compliance with federal regulations within IDEIA. Another possible reason for the observed variability (expressed as SDs in Table 1) may be the way school psychologists practice the profession. For example, some school psychologists may administer more assessment instruments, take longer to administer an assessment instrument, or administer more assessments when completing an evaluation, when compared to other school psychologists.

The purpose of a RTI model is to provide research-based interventions to students who are not meeting grade-level expectations. The foundation of RTI (e.g., Compton, 2008; Fuchs, 2003) and other similar models advocating the implementation of research-based interventions with data-based progress monitoring and decisionmaking is early identification of risk and the provision of intervention services. A key goal within these models is to target a student's specific academic weakness (e.g., phonological awareness, word identification, word meaning, fluency, and reading comprehension) with interventions that will improve their academic knowledge and skills without the need for exceptional education services. Current education standards provided by the National Association of School Psychologists for training program approval requires graduates to have competency in the identification of students' specific academic and/or behavioral weakness, identification and implementation of research-based interventions, data-based progress monitoring, data-based decision-making, as well as consultation to assist teachers and school-based staff to improve the learning outcomes of students not meeting grade-level expectations. Thus, school psychologists are trained to provide direct and indirect intervention services to students who might otherwise be evaluated for a learning or behavioral/emotional disability. One implication of these results is that each student who is suspected of having a learning disability that is successful in an early intervention service model frees up about five hours of a school psychologist's time in psychoeducational assessment activities, as presented in Table 1. Therefore, it may be more efficient for school psychologists to allocate time in direct and indirect service delivery within an early intervention model, when compared to conducting psychoeducational evaluations.

A final implication of the study relates to time spent in meetings. This is one component of the evaluation process that directly involves other education professionals. It is important for education professionals and policy makers to keep in mind that several staff members may be involved in these meetings. For example, as presented in Table 1, the time that school psychologists spend in meetings with a team of education professionals and parents to determine the presence or absence of a learning disability, in aggregate and on average, lasts 81.4 minutes. If a legal education agency (LEA) representative, exceptional/special education teacher, and traditional classroom teacher are also present in the meeting, the total number of team member hours spent in meetings related to learning disability 
eligibility is over five and a half hours (81.4 minutes x 4 education professionals/60) per student. Taken together, these data may quantify the importance of having policies and procedures in place at the school/district level to ensure the efficient use of education professionals' time in team meetings. Providing policies to ensure efficiency in meetings may be the easiest way to increase the time efficiency of school psychologists, LEAs, and school-based staff. This will potentially result in education professionals' ability to spend more time providing direct and indirect services to students and lead to improvement in student outcomes.

\section{LIMITATIONS}

The results from this study are limited by participants' self-selection to attend a national school psychology conference. Thus, there may be differences in the time allocation of school psychologists in psychoeducational evaluation activities who self-selected to attend a national conference and those who elect not to attend. Future research in this area may address this issue via emailed surveys to identify if mean differences exist in the professional practice between school psychologists who attend professional conferences and those who do not.

\section{AUTHOR INFORMATION}

Gordon E. Taub, Ph.D., is a faculty member at the University of Central Florida in the School Psychology Program. His focus of research is on issues relating to academic achievement, assessment, intelligence, and school psychology.

Jennifer Valentine received her Ed.S. in School Psychology from the University of Central Florida. She works with Palm Beach County Public School System and also has a private practice where she specializes in working with children who have emotional/behavioral disorders, intellectual disabilities, and giftedness.

\section{REFERENCES}

1. Axelrod, B. (2001). Administration duration for the Wechsler Adult Intelligence Scale - III and Wechsler Memory Scale - III. Clinical Neuropsychology. 19 (2), 281-288.

2. Axelrod, B. (2002). Validity of the Wechsler abbreviated scale of intelligence and other very short forms of estimating intellectual functioning. Assessment. 9 (1), 17-23.

3. Compton, D. L. (2008). The promise and potential challenges of RTI: data-based evaluations of the concept and related practices. Learning and Individual Differences, 18, $286-287$.

4. Donders, J. (2001). Using a short form of the WISC-III: Sinful or Smart? Child Neuropsychology. 7 (2), 99-103.

5. $\quad$ Fagan, T. K. \& Wise, P. S. (2007) School Psychology: Past, Present, and Future. Bethesda, MD: National Association of School Psychologists.

6. Flanagan, D. P., Fiorello, C. A., \& Ortiz, S. O. (2010). Enhancing practice through application of cattell-Horn-Carroll theory and research: A "Third Method" approach to specific learning disability identification. Psychology in the Schools, 47 (7),739-760.

7. Fischetti, B. (2005). Psychological evaluation time and components: Connecticut suburban practices. NASP Communiqué. 29 (1).

8. Fuchs, L. S. (2003). Assessing intervention responsiveness: conceptual and technical issues. Learning Disabilities Research \& Practice, 18(3), 172-186.

9. Hutton, J., Dubes, R. (1992). Assessment practices of school psychologists: Ten years later. School Psychology Review. 21 (2).

10. Imich, A. (1999). Educational psychologists and the allocation of time. Educational Psychology in Practice. 15 (2), 89-97.

11. Ryan, J., Lopez, S., Werth, T. (1998). Administration time estimates for WAIS-III subtests, scales, and short forms in a clinical sample. Journal of Psychoeducational Assessment. 16, 315-323.

12. Silva, A. (2003). Who are School Psychologists? Retrieved November 20, 2007 from http://www.nasponline.org/about_sp/whatis.aspx

13. Smith, D. (1984). Role and functions of school psychologists: Their characteristics, activities, and populations served. Professional Psychology: Research and Practice. 15, 798-810.

14. Thomas, A. (1999). School psychology 2000: A national database. NASP Communiqué. 28 (3). 
Table 1: Average Total Time in Minutes to Complete

Four Psychoeducational Assessment Activities Across Three Eligibility Areas

\begin{tabular}{|c|c|c|c|c|c|}
\hline Eligibility Area & File Review & $\begin{array}{c}\text { Test Set-up Locate } \\
\text { Child \& Rapport } \\
\text { Building }\end{array}$ & $\begin{array}{l}\text { Test Administration, } \\
\text { Scoring \& Report } \\
\text { Writing }\end{array}$ & $\begin{array}{l}\text { Time in } \\
\text { Meetings }\end{array}$ & Total Time \\
\hline Learning & $\begin{array}{c}29.59 \\
(\mathrm{SD} 15.52)\end{array}$ & $\begin{array}{c}23.26 \\
(\mathrm{SD} 13.66)\end{array}$ & $\begin{array}{c}159.67 \\
(\mathrm{SD} 63.94)\end{array}$ & $\begin{array}{c}81.40 \\
(\mathrm{SD} 35.95)\end{array}$ & $\begin{array}{c}296.26 \\
(\mathrm{SD} 77.77)\end{array}$ \\
\hline Behavior/Emotional & $\begin{array}{c}39.51 \\
(\mathrm{SD} 25.81)\end{array}$ & $\begin{array}{c}27.96 \\
(\mathrm{SD} 14.7)\end{array}$ & $\begin{array}{c}184.49 \\
(\mathrm{SD} 73.95)\end{array}$ & $\begin{array}{c}100.86 \\
(\mathrm{SD} 64.06)\end{array}$ & $\begin{array}{c}355.53 \\
(\mathrm{SD} 103.48)\end{array}$ \\
\hline Intellectual & $\begin{array}{c}31.45 \\
\text { (SD 16.89) }\end{array}$ & $\begin{array}{c}23.47 \\
\text { (SD 11.52) }\end{array}$ & $\begin{array}{c}146.86 \\
(\mathrm{SD} 65.77)\end{array}$ & $\begin{array}{c}83.54 \\
\text { (SD 29.86) }\end{array}$ & $\begin{array}{c}285.27 \\
(\mathrm{SD} 79.64)\end{array}$ \\
\hline
\end{tabular}

Note. $\mathrm{SD}=$ Standard Deviation 
NOTES 